\title{
Bioinspired solar anti-icing/de-icing surfaces based on phase-change materials
}

\author{
Siyu Sheng ${ }^{1}$, Zhicheng Zhu ${ }^{3}$, Zhanhui Wang ${ }^{1}$, Tongtong $\mathrm{Hao}^{1}$, Zhiyuan $\mathrm{He}^{1^{*}}$ and Jianjun Wang ${ }^{1,2^{*}}$
}

\begin{abstract}
Solar anti-icing/de-icing is an environmentally friendly way to convert light energy into heat with the purpose of melting/removing ice. However, the inherent intermittency of solar irradiation limits the application of solar-thermal energy-conversion technologies, when continuous de-icing is required. Herein, we investigate a solar phase-change material (SPCM) that consists of expanded graphite (EG)/paraffin/ polydimethylsiloxane (PDMS), which can not only perform the solar-thermal conversion but also release/store thermal energy. Under sunlight, the SPCM effectively collects and converts the light energy into thermal energy for later antiicing/de-icing. To prepare for a no-light period, e.g., in the evening, the converted thermal energy can be stored in the SPCM using a phase transition. In this way, the energy can be released when needed to keep the temperature of a surface from freezing. The SPCM surface shows excellent anti-icing/ de-icing properties such as a long droplet freeze-delay time $\left(t_{\mathrm{d}}\right.$ $>2 \mathrm{~h})$, even at an ultra-low temperature $\left(-40^{\circ} \mathrm{C}\right)$, using only the light of one sun. This freeze-delay time is much longer than that for a surface without PCM. The tested SPCM surfaces show a high de-icing rate $\left(2.21 \mathrm{~kg} \mathrm{~m}^{-2} \mathrm{~h}^{-1}\right)$ under real-life conditions. In addition, the SPCM shows a high de-icing rate and excellent durability. This study provides a promising route for the utilization of solar energy in anti-icing/de-icing applications.
\end{abstract}

Keywords: bioinspired, phase-change materials, anti-icing/deicing, solar energy, multifunctional

\section{INTRODUCTION}

Unwanted ice formation and accretion create many serious problems for a wide range of applications such as powertransmission systems, shipping, aviation, and outdoor equipment [1-4]. Today, many anti-icing applications still use conventional anti-icing methods such as manual removal, chemical de-icing with fluids, and electric heating $[5,6]$. To overcome the disadvantages of these methods (environmental pollution and high energy consumption), a number of novel passive anti-icing methods were reported to complement existing technologies [711]. In particular, the relatively new approach of using solar anti-icing/frosting surfaces (SASs) has attracted increasing research interest. This method uses solar energy to generate icephobicity [12-15]. The use of SAS is considered an energy- saving and environment-friendly anti-icing approach because solar energy is pollution-free, generally available in most areas, and sustainable. Recently, light-to-heat conversion methods were developed and used for SASs. Relevant approaches include carbon-based methods [16-18], plasmonic-metal-based [8,1921], and semiconductor-based methods [22]. The light-to-heat conversion capability ensures that SAS materials can use heat to delay ice-formation or even melt ice. However, a core problem is often ignored in SAS studies: what happens if there is no sunlight, particularly in the evening? In fact, solar radiation is inherently intermittent, and it is hard to receive sunlight reliably even during the daytime due to weather changes. Storing energy thermally and releasing it when needed is one way to tackle the intermittent-sunlight problem. Thus, it is highly desirable to find SAS materials with the ability to capture, convert, and store solar energy efficiently.

In nature, a special non-freezing plant species, Lobelia telekii, which grows at high altitudes, can store solar thermal energy during daytime and release latent heat at night to avoid freezing $[23,24]$. There is a liquid in Lobelia telekii, which can be considered as a natural phase-change material (PCM) that stores and releases thermal energy. When the temperature is high (above the melting point of PCM, typically during daytime), the PCM melts and absorbs a lot of thermal energy. When the temperature decreases significantly (below the crystallization point of the PCM, typically at night), it releases the stored thermal energy as heat to avoid cooling/freezing. In other words, PCMs automatically manage the balance between demand and supply of thermal energy. Using this method, the plant is able to sustain a temperature above $0^{\circ} \mathrm{C}$, even when the ambient temperature varies between -10 and $10^{\circ} \mathrm{C}$ during the year (Fig. 1a, b).

Following examples found in nature, it may be possible to use this approach for commercial solar anti-icing applications. PCMs are already successfully used in buildings for efficient energy storage [25-29]. The high solar-energy storage capacity, the massive amount of latent heat, and the constant phasechange temperature make PCMs promising candidates for solar anti-icing applications [30-32]. Therefore, it is highly desirable to design and fabricate solar PCMs (SPCMs) with sufficient capability to capture, convert, and store solar-energy efficiently. In this study, we prepared round-the-clock SPCMs that consist of expanded graphite (EG)/paraffin/polydimethylsiloxane (PDMS), and combined solar-thermal conversion with thermal

\footnotetext{
${ }^{1}$ Key Laboratory of Green Printing, Institute of Chemistry, Chinese Academy of Sciences, Beijing 100190, China

${ }^{2}$ School of Future Technology, University of Chinese Academy of Sciences, Beijing 100049, China

${ }^{3}$ Zhong Neng Power-Tech Development CO., LTD., Beijing 100037, China

* Corresponding authors (emails: hezy@iccas.ac.cn (He Z); wangj220@iccas.ac.cn (Wang J))
} 

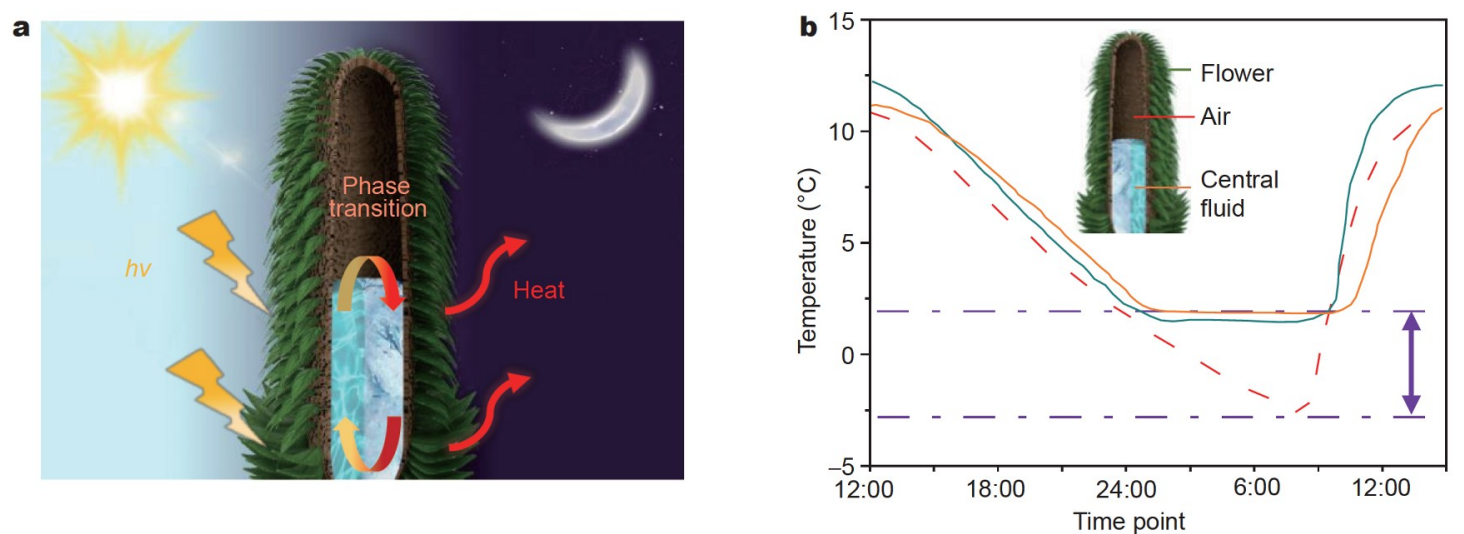

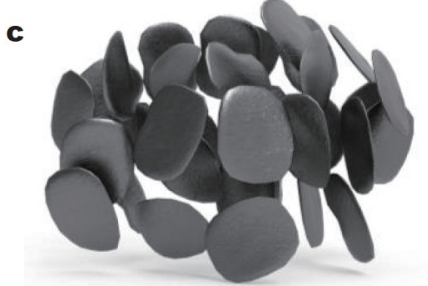

Expandable graphite

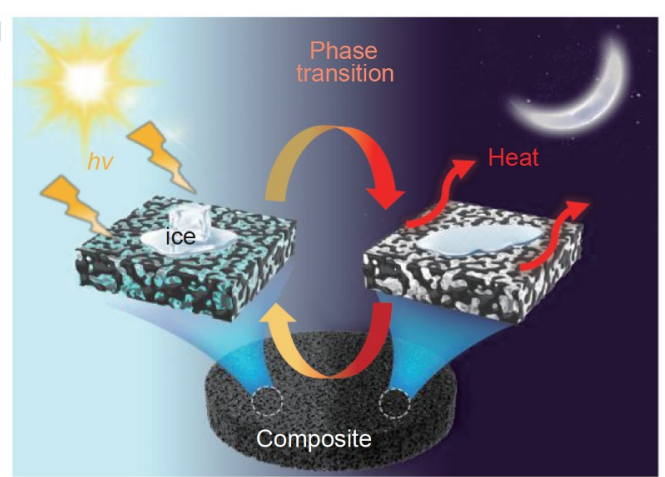

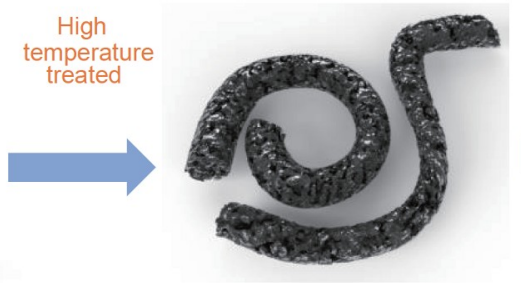

Expanded graphite

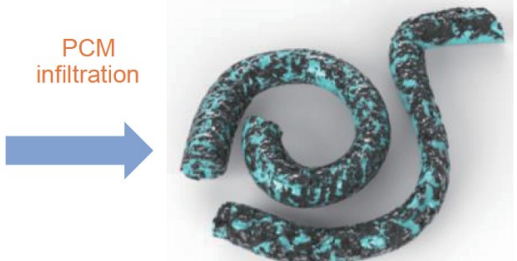

Expanded graphite with PCM

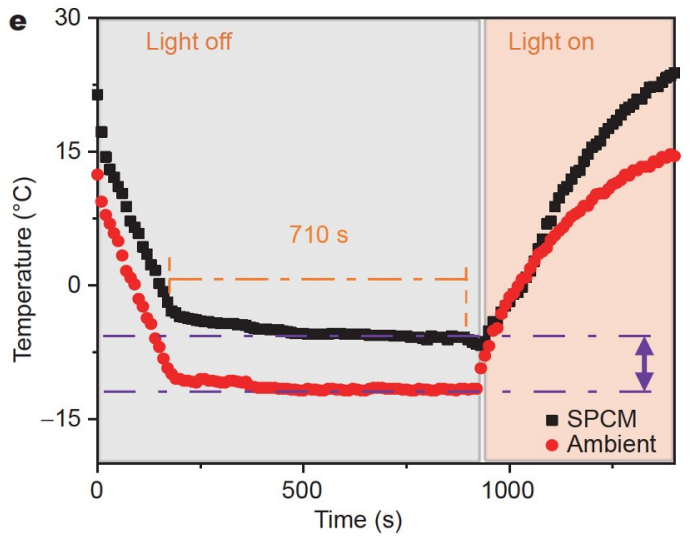

Figure 1 (a) Schematic showing solar thermal energy conversion and storage of the afro-alpine plant species Lobelia telekii. (b) Temperature variation in the flower/central fluid of the plant and the ambient environment during a typical day [23]. (c) Schematic showing the preparation of EG and a PCM composite for solar-thermal conversion and thermal-energy storage. (d) Schematic illustrating the solar-thermal energy conversion and storage in an SPCM. (e) Variation in temperature of the SPCM surface under solar irradiation $\left(100 \mathrm{~mW} \mathrm{~cm}^{-2}\right)$ at an ambient temperature of $-12^{\circ} \mathrm{C}$.

energy storage. The broad light-absorption, efficient solarenergy conversion, high solar-energy-storage capacity, and superior anti-icing/de-icing properties of the SPCM surface make it a promising candidate material for anti-icing/de-icing applications.

\section{EXPERIMENTAL SECTION}

\section{Materials}

Expandable graphite powder was purchased from the company XFNANO. Dodecane, tridecane, tetradecane, pentadecane, and methyl laurate were purchased from Sigma-Aldrich. PDMS prepolymer (SYLGARD 184A) and thermal curing agent (SYLGARD 184B) were purchased from Dow Corning. All these materials were used without further purification.

\section{Composite preparation}

Expandable graphite powder was treated at $900^{\circ} \mathrm{C}$ for $10 \mathrm{~s}$ using a muffle furnace to obtain EG. EG and PCM were mixed toge- ther $(1: 10, w / w)$, and subsequently transferred into a rotary evaporator (for $1 \mathrm{~h}$ under $45^{\circ} \mathrm{C}$ ) to make the PCM fully absorbed in the EG. Subsequently, the EG@PCM composites were thoroughly mixed with PDMS prepolymer in proportion (1:1, 1:2, $1: 3, w / w)$. Then, the mixture was placed in a round mold for shaping. The thickness could be adjusted in this process (5, $10 \mathrm{~mm}$ ). Finally, the mixture in the mold was degassed to remove any air bubbles before thermo-curing. The SPCM was then obtained by curing at $65^{\circ} \mathrm{C}$ for $3 \mathrm{~h}$.

\section{Characterizations}

The surface morphology of all samples was characterized using a scanning electron microscope (SEM, JEOL-JSM-7500F, Japan). The light reflection of the ultraviolet-visible near infrared (UVvis-NIR) spectrum was obtained using a Cary-7000 spectrometer (Agilent, USA). The solar anti-icing experiments were conducted with a solar simulator (CEL-S500, Beijing Au-light Co., Ltd., China), which was equipped with an optical power meter (CEL-NP2000, Beijing Au-light Co., Ltd., China) and an IR 
imaging camera (Tis-55, Fluke, USA). The surface structures of the sample films were measured using attenuated total reflection Fourier-transform infrared (ATR-FTIR) spectroscopy (Bruker TENSOR-27). The distribution of PCM on the samples was characterized using an inverted fluorescence microscope. Differential scanning calorimetry (DSC) data were obtained with a differential scanning calorimeter (Netzsch DSC 204 F1) with sealed $\mathrm{Al}$ pans. The measurements were conducted under $\mathrm{N}_{2}$ flow, with a heating and cooling rate of $5^{\circ} \mathrm{C} \mathrm{min}^{-1}$ ranging from -40 to $40^{\circ} \mathrm{C}$. Thermal conductivity measurements were carried out with a CTHERM TCI spectroscope.

\section{RESULTS AND DISCUSSION}

The preparation process of the SPCM is shown in Fig. 1c. First, expandable graphite was treated at high temperature to obtain EG, which typically yielded a porous structure and large surface area. The PCM (tetradecane) was then infiltrated into the EG using a vacuum adsorption method, which produces the composite material tetradecane@EG. Then, the composite powder tetradecane@EG was blended with PDMS via molding and curing to obtain the SPCM (tetradecane@EG@PDMS). Fig. 1d shows the energy-storing/releasing mechanism of the SPCM surface. When sunlight is available, the SPCM surface can effectively absorb solar irradiation and convert it to heat, while producing anti-icing/de-icing effects. Some of the solar energy can be stored using the phase transition of the SPCM. When there is no sunlight (e.g., in the evening), the ambient temperature begins to decline and approach the crystallization point of the SPCMs. Then, the latent heat is released via the phasetransition, which makes it possible to keep the surface temperature above the freezing temperature of water. The temperature variation curves of the SPCM (black line) and the environment (red line) are plotted in Fig. 1e. The SPCM surface temperature began to decrease with decreasing ambient temperature, when there was no sunlight. When the ambient temperature dropped to $-4^{\circ} \mathrm{C}$, a constant temperature plateau period of the SPCM-surface (lasting $710 \mathrm{~s}$ ) was observed and attributed to the release of stored heat. As a result, the temperature of the SPCM surface was about $10^{\circ} \mathrm{C}$ higher than the ambient temperature. When the light was on, the surface temperature increased quickly due to photothermal effects. These results indicate that the SPCM truly can serve several functions: solar thermal conversion, solar energy storage, and energy release.

The digital photographs in Fig. 2a-c show the macroscopic morphology of expandable graphite, EG, and SPCM, respec-

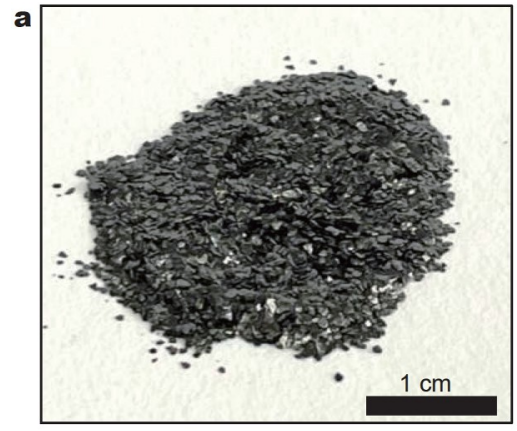

d
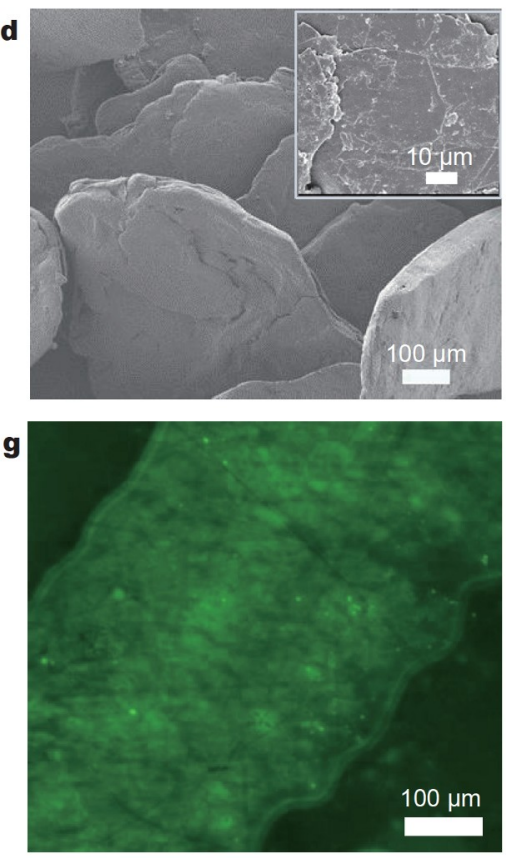

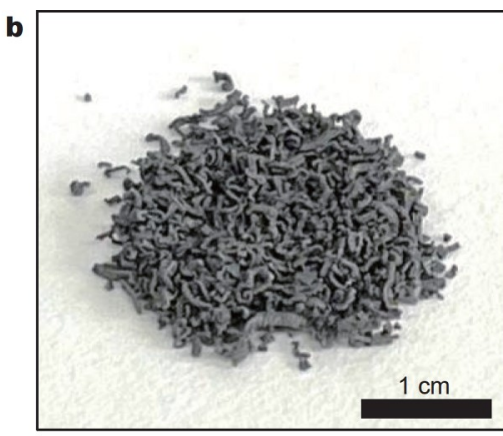

e
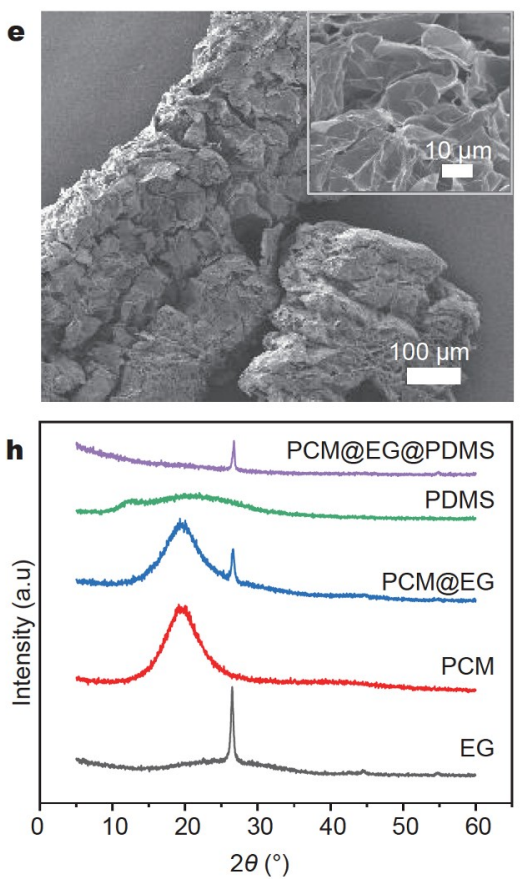

c

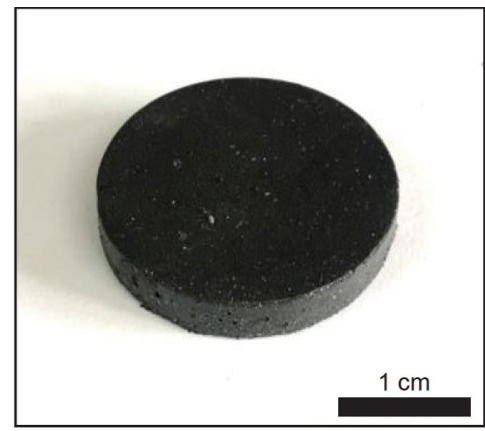

$\mathbf{f}$
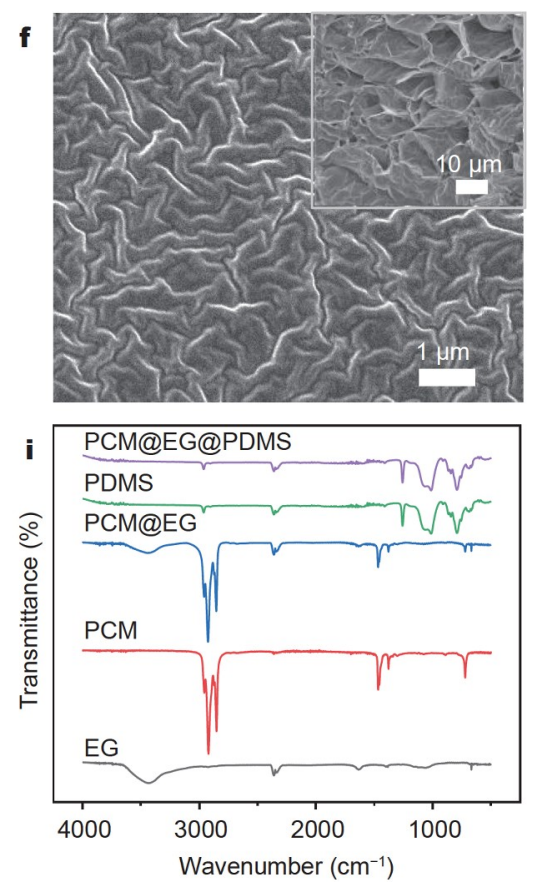

Figure 2 (a-c) Digital photographs of expandable graphite, EG, and SPCM. (d-f) SEM images of expandable graphite, EG, and SPCM. (g) Fluorescence microscopy images of EG with the SPCM. (h) XRD patterns and (i) FT-IR spectra of EG, tetradecane, PDMS, tetradecane@EG, and SPCM. 
tively. The SEM images show that the flake-shaped expandable graphite transforms to wormlike EG with porous structures (Fig. 2d-e). The porous structures further improve the adsorption efficiency of EG. After mixing with the PDMS and curing, the SPCM surface still has a porous structure, which aids light absorption (Fig. 2f).

The distribution of tetradecane within the SPCM was characterized using fluorescence labeling, and $6 \mathrm{H}$-coumarin was selected as the fluorescence agent. $6 \mathrm{H}$-coumarin and tetradecane were mixed and infiltrated into the EG using vacuum adsorption. The distribution of dyed tetradecane was observed via fluorescence microscopy using an excitation wavelength of $466 \mathrm{~nm}$. The fluorescence-microscopy images of EG with dyed tetradecane are shown in Fig. 2g. It can be seen that dyed tetradecane was uniformly distributed on the surface of the SPCM. The crystalline structures and chemical compositions of tetradecane, EG, PDMS, and SPCM were analyzed using X-ray diffraction (XRD) and FT-IR. As can be seen from Fig. 2h, for EG, the diffraction peak at $2 \theta=26.5^{\circ}$ belongs to the (002) crystal plane. Because PCM (tetradecane) and PDMS are amorphous, we can only observe a broad peak. After composing with EG, the characteristic diffraction peak of the (002) crystal plane can be observed for the composite, indicating that the composite SPCM was well assembled. Moreover, as can be seen from the FTIR spectra, the characteristic vibration peaks of the EG around 3458 and $1631 \mathrm{~cm}^{-1}$ correspond to the $-\mathrm{OH}$ bond and $\mathrm{C}=\mathrm{C}$ bond, respectively. PCM exhibits three peaks around 2921, 1468 and $721 \mathrm{~cm}^{-1}$, which can be attributed to the $\mathrm{C}-\mathrm{H}$ bond. PDMS shows that two peaks (around 797 and $1080 \mathrm{~cm}^{-1}$ ) correspond to the $\mathrm{Si}-\mathrm{O}$ bond, and another peak (around $1260 \mathrm{~cm}^{-1}$ ) corresponds to the $\mathrm{Si}-\mathrm{C}$ bond. It is notable that the composite shows all characteristic peaks of all components, which indicates the successful integration of the SPCM.

It is the PCM that endows the composite with the thermal storage capability. To verify the most suitable PCM for anti-icing applications, we selected methyl laurate, pentadecane, tetradecane, tridecane, and dodecane as PCMs. The thermophysical properties of these PCMs were investigated using DSC. The load of the PCM indicates the energy-storage capacity of the composite. As the load of the PCM increases, the energy-storage capacity increases as well. However, for an increasing amount of PCM, the leakage of PCM also needs to be avoided. The maximum PCM capacity of EG was verified by a leakage-experiment and yielded the mass ratio 1:10 $(w / w)$ (see Fig. S1). The ratio of PCM to EG was also studied (see Fig. S2). As the fraction of PCM increases, the samples can maintain the temperature constant for a longer time period. Hence, we chose the 1:10 ratio in this work. Fig. 3a-c show the DSC curves of different samples before and after compounding. As shown by the DSC measurements in Fig. 3a, different PCMs have different phasechange temperatures. For the application in anti-icing, the PCMs should possess a high latent heat for the phase transition, and the phase-change temperature should be close to zero. In this way, the latent heat can be released when approaching the freezing point. It can be seen that, after combining with EG and PDMS, the PCMs still maintained the ability to release latent heat. After a comparison of the different PCMs with regard to phase-change temperature and enthalpy (Tables S1-S3), we
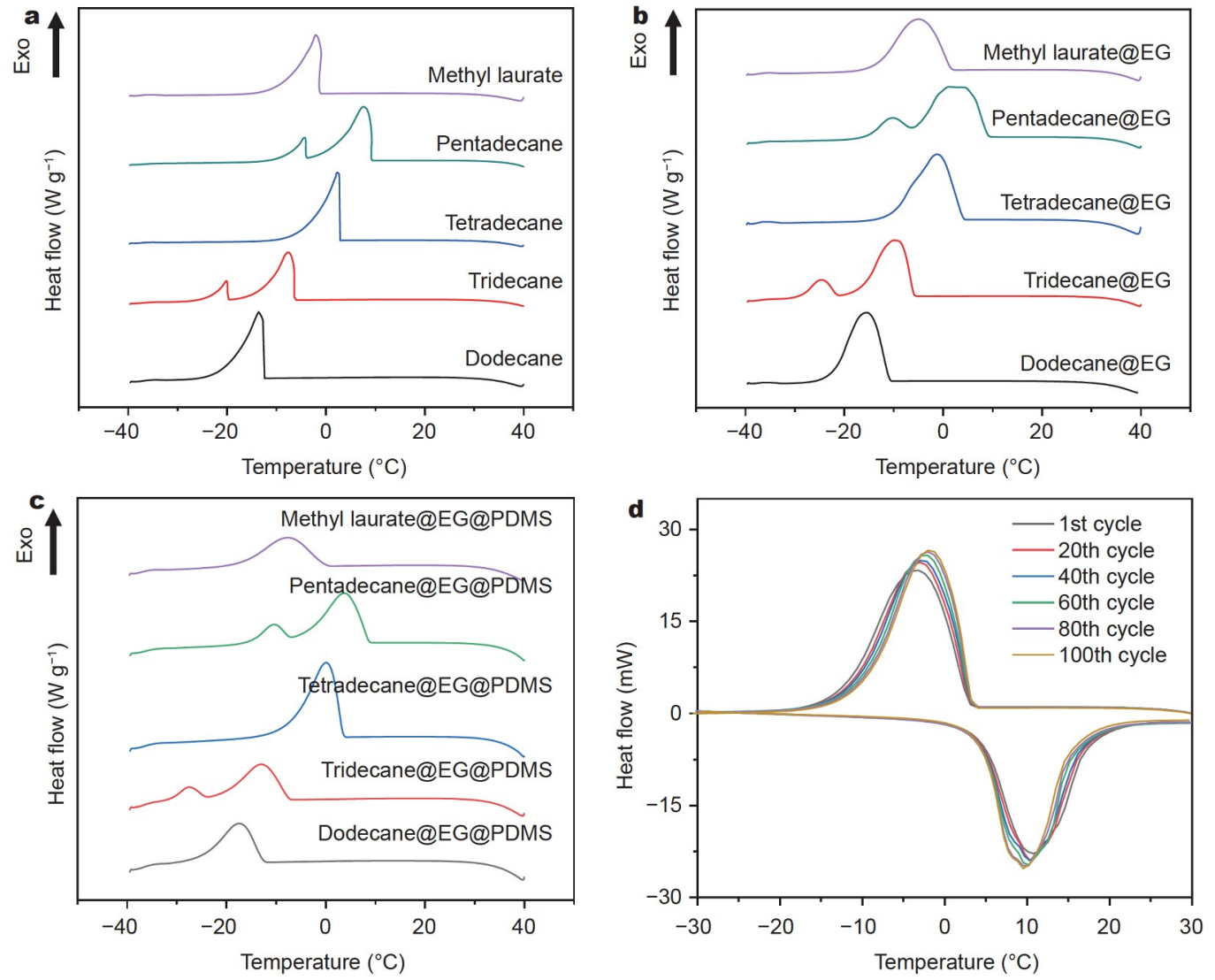

Figure $3(\mathrm{a}-\mathrm{c})$ The phase transitions for different samples were studied using DSC measurements. (d) Stabilization-test results for the SPCM for 100 cycles of DSC scanning. 
chose tetradecane. It has a suitable phase-change temperature and the highest enthalpy $\left(-0.1^{\circ} \mathrm{C}, 95.01 \mathrm{~J} \mathrm{~g}^{-1}\right)$. Table 1 summarizes the thermal characteristics of tetradecane. In addition, the composite shows good thermal stability. After 100 melting/ freezing cycles, the melting enthalpy of the composite shows only a negligible change. This is good news for the required repeated use of the SPCM (Fig. 3d). The compressive strength of the SPCM was also studied (Fig. S3).

Fig. 4a shows the reflection-spectra $(295-2500 \mathrm{~nm}$, the solar spectrum ranges from 295 to $2500 \mathrm{~nm}$ on the earth surface) for PDMS, EG@PDMS, and SPCM-a-c (SPCM-a-c represent $m$ (PCM@EG): $m$ (PDMS) $=1: 1,1: 2,1: 3$, respectively. The thickness of all samples was $5 \mathrm{~mm}$ ). It can be found that all composite samples with EG feature a clearly lower reflectance compared with pure PDMS, and, as the PCM@EG content increased from 25 to $50 \mathrm{wt} \%$, a slight increase in the surface reflectance can be observed. This indicates that the EG is mostly responsible for the observed light absorption.

To confirm the energy-storage capability of the composite, the light was turned off after 25-min irradiation, at an environmental temperature of $-20^{\circ} \mathrm{C}$, and the temperature-change curves of the samples were recorded with an IR camera (see Fig. 4b). Under light irradiation, the light was absorbed by the
EG in the composite and converted to heat. This increased the temperature of the composite and triggered a phase change (melting) of the PCM in the composite, which enabled the storing of thermal energy (Fig. 4b). After the light was turned off, the temperature began to decline. A temperature-plateau could be clearly observed in the PCM composite, and this is the expected result of the stored-heat-release by the PCM. On the other hand, the same phenomenon was not observed in the composite without PCM, which quickly cooled down to ambient temperature. After comparing the samples SPCM-a-c, we can see that, as the content of PDMS increased, both heating and cooling rates of the composite decreased significantly. This is caused by the decrease in thermal conductivity, and a low thermal conductivity can potentially interrupt the heat transfer. Table S4 shows the thermal conductivity of different samples. In addition, the PDMS increase means a loss of PCM@EG content, which leads to heat-storage- and heat-release-capacity decrease. Thus, the balance between the portion of PDMS and PCM@EG should be carefully adjusted. The sample SPCM-b with medium portion ( $m$ (PCM@EG): $m(\mathrm{PDMS})=1: 2)$ shows the best energy storage and release properties.

It can also be seen that the plateau time increases (SPCM-d, $10 \mathrm{~mm}$ ) as the thickness of the composite increases. The tem-

Table 1 Thermophysical properties of tetradecane, tetradecane@EG, and SPCM

\begin{tabular}{ccccc}
\hline Sample & $T_{\mathrm{m}}\left({ }^{\circ} \mathrm{C}\right)$ & $\Delta H_{\mathrm{m}}\left(\mathrm{J} \mathrm{g}^{-1}\right)$ & $T_{\mathrm{f}}\left({ }^{\circ} \mathrm{C}\right)$ & $\Delta H_{\mathrm{f}}\left(\mathrm{J} \mathrm{g}^{-1}\right)$ \\
\hline Tetradecane & 5.86 & 192.7 & 2.61 & 193.4 \\
Tetradecane@EG & 8.38 & 188.8 & -5.07 & 182.3 \\
Tetradecane@EG@PDMS & 5.32 & 106 & -0.1 & 95.01 \\
\hline
\end{tabular}
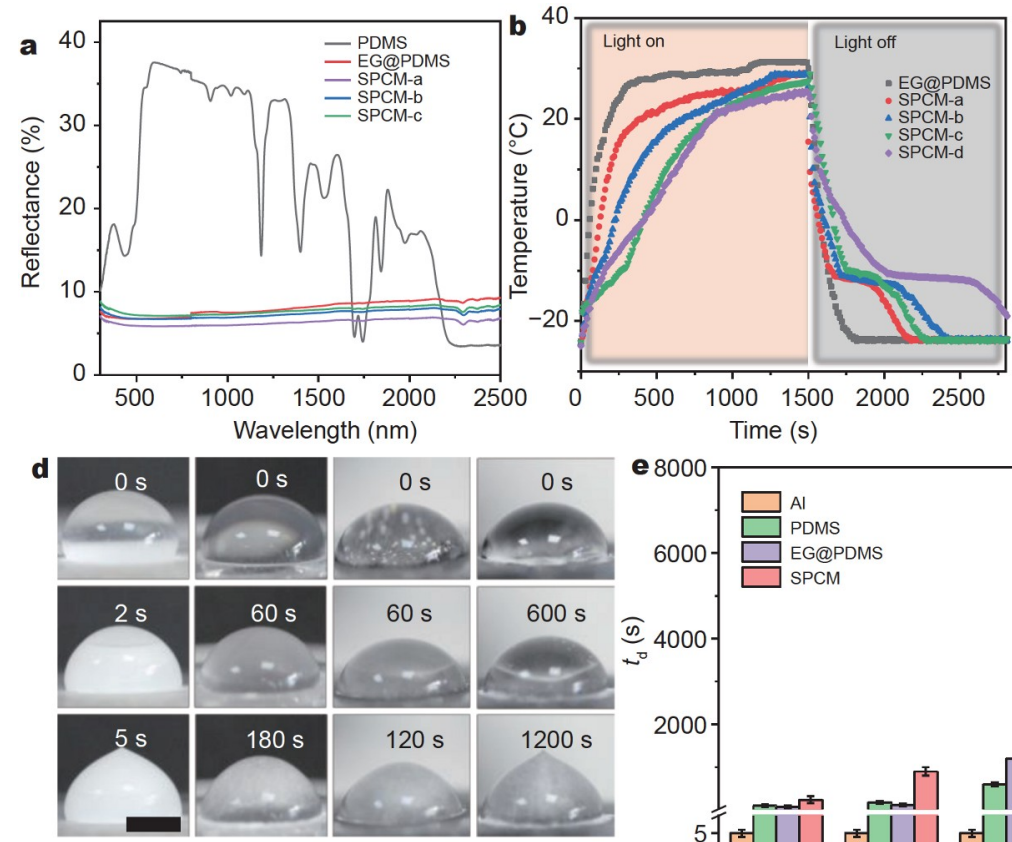

$\mathrm{Al}$
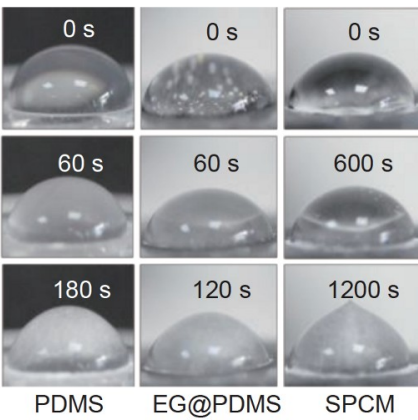

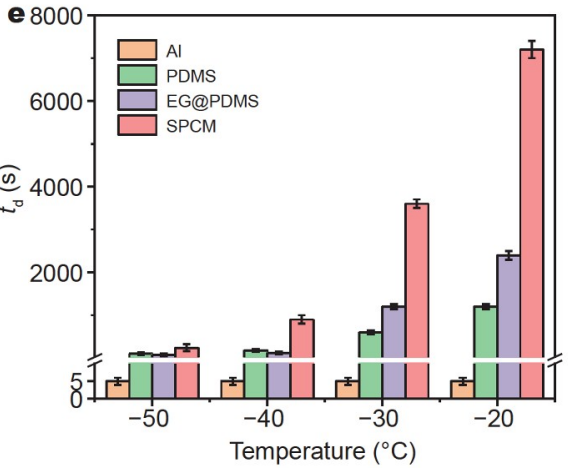

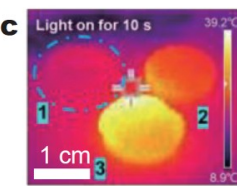
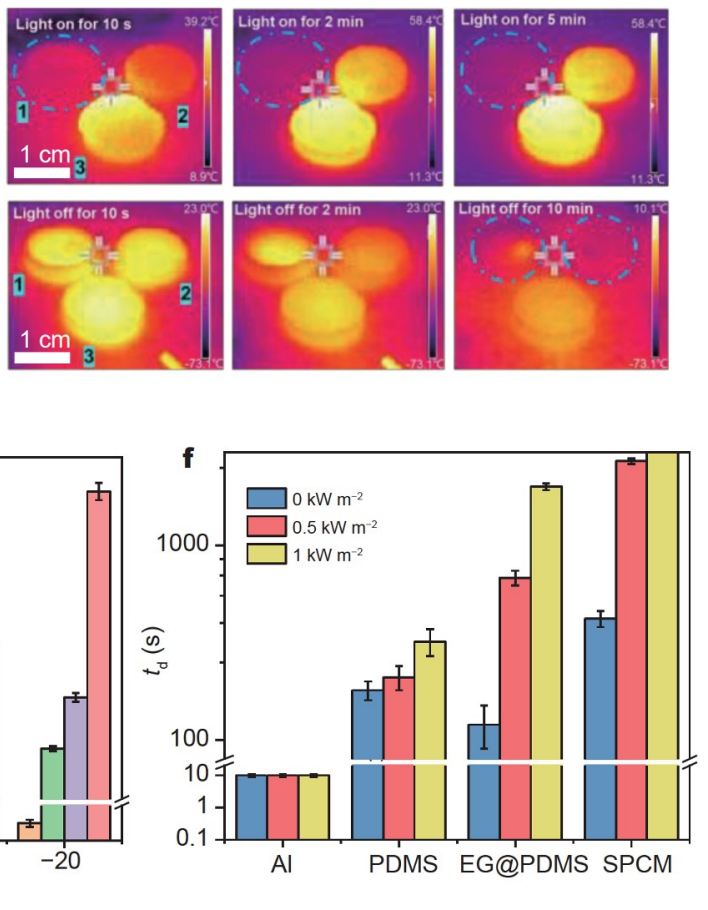

Figure 4 (a) UV-vis-NIR reflectance spectra of the PDMS-based samples. SPCM-a-c represent $m(\mathrm{PCM} @ E G): m(\mathrm{PDMS})=1: 1,1: 2,1: 3$, respectively. The thickness of all samples was $5 \mathrm{~mm}$. (b) Surface-temperature variation of different samples under one sun illumination. SPCM-a-c represent $m$ (PCM@EG): $m($ PDMS $)=1: 1,1: 2,1: 3$, respectively. SPCM-d represents $m$ (PCM@EG): $m($ PDMS) = 1:2. The thicknesses for SPCM-a-c and SPCM-d were 5 and 10 mm. (c) Thermal images of the samples when light was switched (on/off) (1: PDMS; 2: EG@PDMS; 3: SPCM). (d) Optical microscopy images of water droplets freezing at $-40^{\circ} \mathrm{C}$ for different samples without light. The scale bar is $250 \mu \mathrm{m}$. (e) Freezing-delay time ( $t_{\mathrm{d}}$ ) of the water droplet on different samples at different temperatures. (f) $t_{\mathrm{d}}$ of the water droplet on different samples and different light intensities at $-40^{\circ} \mathrm{C}$. 
perature plateau is different from the freezing point obtained by the DSC test because the IR camera was not completely accurate, especially in a low-temperature environment. Therefore, the temperature curves in Fig. $4 \mathrm{~b}$ mainly serve as a guide for the temperature-change tendency. The solar-thermal energy-storage efficiency $(\eta)$ of the composite under light was estimated using the ratio of the stored thermal energy to the received light energy:

$\eta=\frac{Q_{\mathrm{S}}}{Q}=\frac{m \times \Delta H}{P \times A \times t}$,

where $Q_{\mathrm{S}}$ is the stored thermal energy by the composite, $Q$ is the received light energy by the composite, $m(1.8750 \mathrm{~g})$ is the mass of the composite sample, $P$ is the intensity of the simulated solar light, $A\left(3.14 \mathrm{~cm}^{2}\right)$ is the surfaces area of the composite exposed to light, $t$ is the duration of light irradiation for heating the composite from a lower temperature $\left(T_{1}\right)$ to a higher temperature $\left(T_{2}\right)$, and $\Delta H$ is the enthalpy change of the composite in the temperature range $\left(T_{1}-T_{2}\right)$ that can be obtained by the DSC measurements. Under simulated solar irradiation, with a light intensity of $1000 \mathrm{~W} \mathrm{~m}^{-2}$, when the temperature of the composite increased to 8 from $-15^{\circ} \mathrm{C}$, which corresponds to an enthalpy chang $(\Delta H)$ of $95.01 \mathrm{~J} \mathrm{~g}^{-1}$, the storage efficiency $(\eta)$ was calculated to be $81.04 \%$ for this period.

Thermal images were recorded to show the temperature changes for PDMS, EG@PDMS, and SPCM directly (Fig. 4c). Under light irradiation, the temperature of samples with EG could increase clearly, while the temperature of pure PDMS did not increase significantly. During the cooling process, after 10 min with the light off, SPCM still maintained a high temperature. On the other hand, the temperature of other samples without PCM decreased to below zero.

The freezing-delay time of the samples was then studied in more detail. The freezing-delay time $\left(t_{\mathrm{d}}\right)$ on the different surfaces varied significantly without light irradiation at $-40^{\circ} \mathrm{C}$ (Fig. $4 \mathrm{~d}$, e). The droplet on the Al surface froze within $5 \mathrm{~s}$, while for the PDMS surface and EG@PDMS surface, the freezing-time delays were 180 and $120 \mathrm{~s}$, respectively. In contrast, the droplet on the SPCM surface remained unfrozen state for more than $600 \mathrm{~s}$. However, the droplets froze completely after $1200 \mathrm{~s}$. It is the PCM's released latent heat and low thermal conductivity that was responsible for the long freeze-delay time. The freeze-delay time was also affected by temperature and light intensity. When the temperature was below $-40^{\circ} \mathrm{C}$, the droplets on all surfaces froze quickly, and, as the ambient temperature increased, $t_{\mathrm{d}}$ increased significantly. When the samples were exposed to light, the $t_{\mathrm{d}}$ was further increased because EG converts light into heat. This increased the surface temperature, and the water droplet remained in the unfrozen state for more than $2 \mathrm{~h}$ when light illumination intensity was $1 \mathrm{~kW} \mathrm{~m}^{-2}$ (Fig. 4f).

The ice-removal performance of the composite was investigated by simulating a day/night alternation. The samples were exposed to an ambient environment at $-20^{\circ} \mathrm{C}$ with a relative humidity $(\mathrm{RH})$ at $20 \% \pm 5 \%$ with light off/on every $1 \mathrm{~h}$. Ice coverage of the samples is shown in Fig. $5 \mathrm{a}$, b. After $60 \mathrm{~min}$, both the PDMS surface and the SPCM surface were completely covered by frost. Then, upon light irradiation, the frost on the SPCM melted within 5 min, while the PDMS surface remained covered with frost. Three cycles were conducted and the SPCM could demonstrate repeated frost growth and frost removal. On the other hand, the PDMS surface was always covered with frost regardless whether there was light or not. Subsequently, a
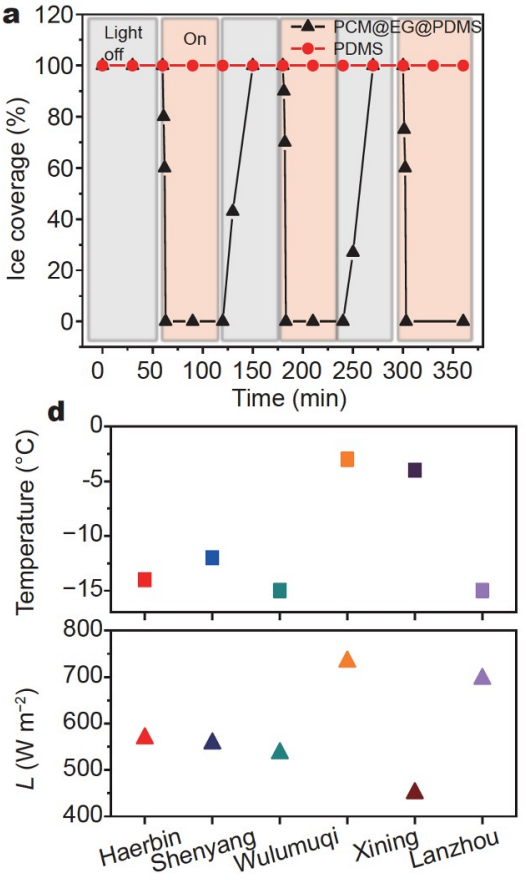

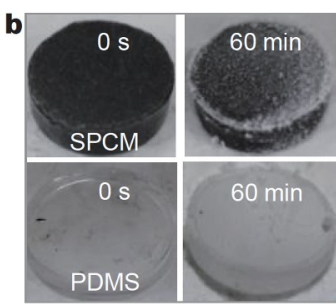

Light off

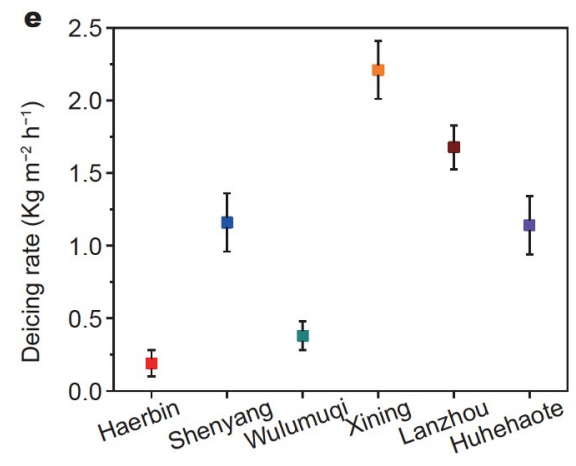

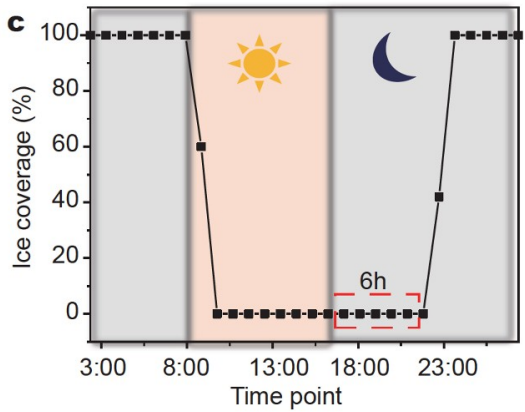

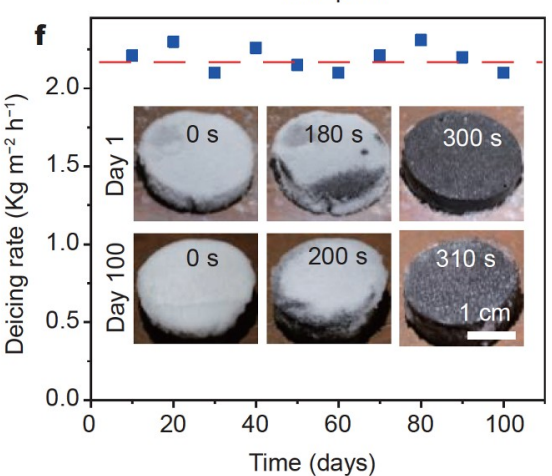

Figure 5 (a) Ice coverage of the sample for solar irradiation simulated day and night $\left(q_{\mathrm{i}}=100 \mathrm{~mW} \mathrm{~cm}^{-2}\right)$. (b) Digital images of the frosting- and defrostingprocess for the different samples for solar irradiation simulated day and night. (c) Simulation of ice-coverage properties for the SPCM for one day $\left(-10^{\circ} \mathrm{C}\right.$ with humidity of 20\%). (d) Data related to average temperatures and solar intensities, which were collected in January for six cities in China. (e) De-icing rates for each simulated environment. (f) Solar de-icing performance of SPCM over a long period. The insets show typical solar de-icing for day 1 and day 100. (5-mmthick films were used in all experiments). 
simulation of ice coverage behavior for the SPCM for one day in Xining was performed. The ice-delay time of the SPCM was about $6 \mathrm{~h}$, after the sunlight disappeared. Moreover, six typical cities in northern China, which undergo different icing conditions (Fig. 5d), were selected to test the de-icing property of the composite. Data related to the average temperatures and solar intensities in January for the period from 1990 to 2010 of these six cities were collected. Furthermore, the de-icing rate of the SPCM composite was studied in laboratories by simulating reallife conditions. The results indicate that ice coverage of the SPCM composite in different cities could be avoided/eliminated completely. The only difference was that the de-icing rate was affected by the ambient temperature and light intensity differently in different cities. The de-icing rates for the six cities are shown in Fig. 5e. The city of Xining, which had the highest temperature and light intensity among the six cities, shows the highest de-icing rate $\left(2.21 \mathrm{~kg} \mathrm{~m}^{-2} \mathrm{~h}^{-1}\right)$.

We used Xining as the representative city to investigate the durability of the SPCM composite. The SPCM surface maintained a constant high de-icing rate after many repeated icing/ de-icing cycles over a long period (100 days) (see Fig. 5f). This suggests good durability and long-term anti-icing capabilities.

\section{CONCLUSIONS}

In summary, we have demonstrated a solar-thermal conversion and storage material of SPCMs, and investigated the sustainability of the anti-icing property of the SPCM. Under light irradiation, the SPCM collected and converted light into heat effectively. When there was no light, the stored latent heat (via the phase transition) was successfully released to keep the surface temperature of the SPCM above the freezing point of water. As a result, the SPCM surface was able to perform anti-icing functions throughout the day. Furthermore, the SPCM showed a high de-icing efficiency under different (simulated) real-life conditions. Therefore, the durability and robustness make SPCMs promising candidates for commercial anti-icing applications. We believe that this study provides a promising route towards the sustainable utilization of solar energy for anti-icing. However, the mechanical robustness of this SPCM is suboptimal, which may still limit its widespread application in antiicing conditions. The development of SPCMs with robust mechanical properties is still needed.

\section{Received 21 July 2021; accepted 29 October 2021; published online 1 December 2021}

1 Bartels-Rausch T. Ten things we need to know about ice and snow. Nature, 2013, 494: 27-29

2 Lv J, Song Y, Jiang L, et al. Bio-inspired strategies for anti-icing. ACS Nano, 2014, 8: 3152-3169

3 Gent RW, Dart NP, Cansdale JT. Aircraft-icing. Philos Trans R Soc London Ser A-Math Phys Eng Sci, 2000, 358: 2873-2911

4 Rashid T, Khawaja HA, Edvardsen K. Review of marine icing and anti-/ de-icing systems. J Mar Eng Tech, 2016, 15: 79-87

5 Dalili N, Edrisy A, Carriveau R. A review of surface engineering issues critical to wind turbine performance. Renew Sustain Energy Rev, 2009, 13: $428-438$

6 Farzaneh M, Ryerson CC. Anti-icing and deicing techniques. Cold Regions Sci Tech, 2011, 65: 1-4

7 Wu S, Du Y, Alsaid Y, et al. Superhydrophobic photothermal icephobic surfaces based on candle soot. Proc Natl Acad Sci USA, 2020, 117: 11240-11246

8 Zhang G, Zhang Q, Cheng T, et al. Polyols-infused slippery surfaces based on magnetic $\mathrm{Fe}_{3} \mathrm{O}_{4}$-functionalized polymer hybrids for enhanced multifunctional anti-icing and deicing properties. Langmuir, 2018, 34: 4052-4058

9 He Z, Liu K, Wang J. Bioinspired materials for controlling ice nucleation, growth, and recrystallization. Acc Chem Res, 2018, 51: 10821091

10 Jin $\mathrm{Y}, \mathrm{Wu} \mathrm{C}$, Yang $\mathrm{Y}$, et al. Inhibiting condensation freezing on patterned polyelectrolyte coatings. ACS Nano, 2020, 14: 5000-5007

11 Wang Y, Yao X, Chen J, et al. Organogel as durable anti-icing coatings. Sci China Mater, 2015, 58: 559-565

12 Cheng $\mathrm{T}, \mathrm{He} \mathrm{R}$, Zhang Q, et al. Magnetic particle-based super-hydrophobic coatings with excellent anti-icing and thermoresponsive deicing performance. J Mater Chem A, 2015, 3: 21637-21646

13 Yin $\mathrm{X}$, Zhang $\mathrm{Y}$, Wang $\mathrm{D}$, et al. Integration of self-lubrication and nearinfrared photothermogenesis for excellent anti-icing/deicing performance. Adv Funct Mater, 2015, 25: 4237-4245

14 Matsubayashi $\mathrm{T}$, Tenjimbayashi $\mathrm{M}$, Manabe $\mathrm{K}$, et al. Integrated antiicing property of super-repellency and electrothermogenesis exhibited by PEDOT:PSS/cyanoacrylate composite nanoparticles. ACS Appl Mater Interfaces, 2016, 8: 24212-24220

15 Dash S, de Ruiter J, Varanasi KK. Photothermal trap utilizing solar illumination for ice mitigation. Sci Adv, 2018, 4: eaat0127

16 Ren H, Tang M, Guan B, et al. Hierarchical graphene foam for efficient omnidirectional solar-thermal energy conversion. Adv Mater, 2017, 29: 1702590

17 Wu C, Geng H, Tan S, et al. Highly efficient solar anti-icing/deicing via a hierarchical structured surface. Mater Horiz, 2020, 7: 2097-2104

18 Jiang G, Chen L, Zhang S, et al. Superhydrophobic SiC/CNTS coatings with photothermal deicing and passive anti-icing properties. ACS Appl Mater Interfaces, 2018, 10: 36505-36511

19 Mitridis E, Schutzius TM, Sicher A, et al. Metasurfaces leveraging solar energy for icephobicity. ACS Nano, 2018, 12: 7009-7017

20 Ma L, Wang J, Zhao F, et al. Plasmon-mediated photothermal and superhydrophobic TiN-PTFE film for anti-icing/deicing applications. Compos Sci Tech, 2019, 181: 107696

21 Razzaq MY, Behl M, Lendlein A. Memory-effects of magnetic nanocomposites. Nanoscale, 2012, 4: 6181-6195

22 Walker C, Mitridis E, Kreiner T, et al. Transparent metasurfaces counteracting fogging by harnessing sunlight. Nano Lett, 2019, 19: 1595-1604

23 Krog JO, Zachariassen KE, Larsen B, et al. Thermal buffering in afroalpine plants due to nucleating agent-induced water freezing. Nature, 1979, 282: 300-301

24 Zachariassen KE, Kristiansen E. Ice nucleation and antinucleation in nature. Cryobiology, 2000, 41: 257-279

25 Sarı A, Karaipekli A. Fatty acid esters-based composite phase change materials for thermal energy storage in buildings. Appl Thermal Eng, 2012, 37: 208-216

26 Aftab W, Huang X, Wu W, et al. Nanoconfined phase change materials for thermal energy applications. Energy Environ Sci, 2018, 11: 13921424

27 Mehrali M, ten Elshof JE, Shahi M, et al. Simultaneous solar-thermal energy harvesting and storage via shape stabilized salt hydrate phase change material. Chem Eng J, 2021, 405: 126624

28 Zhang L, Li R, Tang B, et al. Solar-thermal conversion and thermal energy storage of graphene foam-based composites. Nanoscale, 2016, 8: 14600-14607

29 Tong X, Li N, Zeng M, et al. Organic phase change materials confined in carbon-based materials for thermal properties enhancement: Recent advancement and challenges. Renew Sustain Energy Rev, 2019, 108: $398-422$

30 Zhu K, Li X, Su J, et al. Improvement of anti-icing properties of low surface energy coatings by introducing phase-change microcapsules. Polym Eng Sci, 2018, 58: 973-979

31 Chatterjee R, Beysens D, Anand S. Delaying ice and frost formation using phase-switching liquids. Adv Mater, 2019, 31: 1807812

32 Abdeali G, Bahramian AR, Abdollahi M. Review on nanostructure supporting material strategies in shape-stabilized phase change materials. J Energy Storage, 2020, 29: 101299 
Acknowledgements This work was financially supported by the National Natural Science Foundation of China (21875261, 51925307 and 21733010), the National Key Research and Development Program of China (2020YFE0100300 and 2018YFA0208502), the Key Research Program of Frontier Sciences, Chinese Academy of Sciences (ZDBS-LYSLH031), and the Youth Innovation Promotion Association of the Chinese Academy of Sciences (2018044).

Author contributions Wang J and $\mathrm{He} \mathrm{Z}$ designed the experiments; Sheng $\mathrm{S}$ performed the experiments; Wang J, He Z, Wang Z and Zhu Z supervised the theoretical and experimental work. Sheng $\mathrm{S}$ and $\mathrm{He} \mathrm{Z}$ wrote the manuscript. All authors contributed to the general discussion and reviewed the manuscript.

Conflict of interest The authors declare that they have no conflict of interest.

Supplementary information Supporting data are available in the online version of the paper.

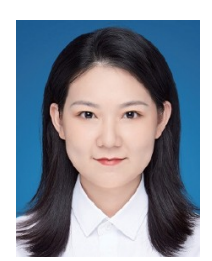

Siyu Sheng obtained her master degree at the College of Chemistry, Beijing University of Chemical Technology in 2020. She has been a research assistant at the Institute of Chemistry, Chinese Academic of Sciences (ICCAS). Her current research mainly relates to the fabrication and application of polymeric anti-icing materials.

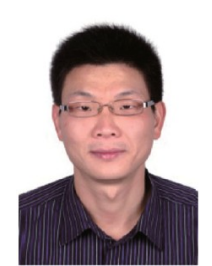

Jianjun Wang obtained his $\mathrm{PhD}$ degree at Max-Planck Institute for Polymer Research and University of Mainz (Germany) in 2006. After his postdoctoral research, he became a project leader at Max-Planck Institute for Polymer Research in 2007. Since 2010, he has been a professor at the ICCAS. His current research is focused on the molecular-level understanding of ice formation and applications such as the cryopreservation of cells.

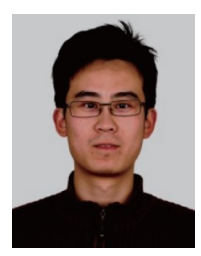

Zhiyuan He obtained his $\mathrm{PhD}$ degree at the ICCAS in 2014. He has been an associate professor at ICCAS. His current research focuses on anti-icing coatings.

\section{基于相变材料的仿生太阳能防冰/除冰材料}

盛思雨 ${ }^{1}$, 朱志成 $^{3}$, 王占辉 ${ }^{1}$, 郝㣌㔙 $^{1}$, 贺志远 ${ }^{*}$, 王健君 ${ }^{1,2^{*}}$

摘要 太阳能除冰是环境友好的新型除冰/防冰方法, 然而太阳能辐射 的间歇性导致光热效率降低, 限制了其发展. 本文以膨胀石墨为光热载 体，通过真空浸渍法将相变剂与之复合，再利用聚二甲基硅氧烷 (PDMS) 热固定型得到光热相变复合材料, 并探究了其光热转化性能与 防冰/除冰能力. 结果表明复合材料不仅能实现光热转化, 同时由于相 变剂的作用能够进行热能的存储与释放, 且表现出优越的防冰/除冰性 能. 在 $-40^{\circ} \mathrm{C}$, 一个太阳光强的条件下, 材料表面的液滴延缓结冰时间超 过 $2 \mathrm{~h}$, 在不同环境温度下表面除冰速率最高可达 $2.21 \mathrm{~kg} \mathrm{~m}^{-2} \mathrm{~h}^{-1}$. 此外, 此光热相变复合材料还表现出极高的可重复利用性. 该材料是一类很 有应用前景的高效光热防冰/除冰材料. 